\title{
Noticias demográficas sobre la región atacameña durante el siglo XVIII*
}

Jose Maria Casassas Cantu**

1. Tenemos en proyecto e inicial desarrollo, lamentablemente demasiado lento por diversas circunstancias, el fichaje de las inscripciones sacramentales eclesiásticas de las parroquias de la actual provincia de Antofagasta, en el período correspondiente a los siglos XVIII y XIX. Este fichaje, en el cual los datos son anotados en forma que permita posteriormente su procesamiento computacional, habrá de constituir, creemos, una apreciable ayuda para la obtención de la base documental indispensable para los estudios de tipo histórico-geográfico y socioeconómico sobre la región atacameña durante los siglos mencionados. En efecto, tal fichaje permitiría recuperar amplios datos relacionados entre sí: localidades, fechas, nombres o apellidos, sexo, edades, características étnicas, filiaciones, pueblos de naturaleza, procedencia y/o residencia, autoridades, cargos y aun algunos otros complementarios. Mediante el proyecto de referencia es de esperar que podría conseguirse una visión bastante completa y llegar a conclusiones de un cierto peso cuantitativo y de un apreciable fundamento científico en lo que se refiere a la región y al período aludidos.

2. En todo caso, debe hacerse constar que para obtener tales logros se presentan notables inconvenientes que difícilmente podrán ser salvados u obviados mediante otras fuentes históricas. Es-

\footnotetext{
Parte del presente trabajo constituyó un artículo, redactado a fines de 1972, que con el título "Algunas noticias demográficas sobre Atacama la Baja (Chiu Chiu) y el territorio de su jurisdicción durante el siglo XVIII" iba a ser publicado en la revista Kuntur, proyectado órgano del Instituto Chileno-Boliviano de Cultura, de Antofagasta. Aunque dicho artículo ha sido ya impreso para ocupar las páginas 13 a 31 del primer número de dicha revista, ésta no ha visto todavía la luz pública por explicables dificultades de la institución editora. Además, mi reciente hallazgo de algunas hojas sueltas de libros parroquiales de Chiuchiu, de los siglos XVIII y XIX, que se encontraron dentro de un legajo que no correspondía, han venido a modificar algunos datos numéricos que se consignaban en dicho artículo para Kuntur.

** Doctor en Historia. Profesor de la Universidad del Norte. Antofagasta.
}

tas dificultades se originan en varias circunstancias:

a) Los libros parroquiales de que disponemos nos han llegado en muchos casos, y esto vale marcadamente para los del siglo XVIII, con apreciables deterioros e incompletos; con muchos vacíos cronológicos por hojas desgajadas, arrancadas y perdidas. A veces, tales vacíos abarcan diversos años correlativos de los que no queda ninguna constancia, ya sea en relación con alguna de las localidades en forma particular o, en otros casos, con todo el conjunto de la parroquia y sus anexos.

b) En otras oportunidades enfrentamos igualmente esta falta de información, tales vacíos, pero no por la causa antes aludida sino, simplemente, porque, por diversos motivos, durante ciertos lapsos no se anotaron las inscripciones que hubieran correspondido. La región atacameña, en su extensa amplitud desértica, áspera, poco poblada, con la pobreza del "sínodo" o renta ${ }^{1}$ que brindaba al párroco o doctrinero, no era evidentemente -materialmente pensando- demasiado atractiva para promover la adhesión a sus curatos. Por esto podemos comprobar frecuentes cambios en los párro$\cos ,{ }^{2}$ ya que algunos, por lo menos, sólo vieron su función en Atacama como un paso, inevitable y poco grato, para aspirar a la consecución de pre-

\footnotetext{
512 pesos anuales, en 1608, según se detalla en el expediente de división del Obispado de La Plata (Archivo General de Indias, Sevilla, Audiencia de Charcas, Legajo 140, hoja 57). 800 pesos anuales en las últimas décadas del siglo XVIII, según afirma Pedro Vicente Cañete y Domínguez en Guía histórica, geográfica, física, política, civil y legal del Gobierno e Intendencia de la Provincia de Potosí, manuscrito original de 1787, publicado en Potosí, Edit. Potosí, 1952, p. 313.

2 Cfr. Casassas Cantú, José María: Relación de los sacerdotes que ejercieron ministerio en la Región Atacameña durante el siglo XVIII y algunos documentos relativos a su misión, en revista Norte Grande del Instituto de Geografía de la Universidad Católica de Chile, Santiago, 1974, Vol I, $\mathrm{N}^{\circ} 1$, pp. 45 a 54.
} 
bendas económicamente mejores, o bien -con enfoques más espirituales-, la consideraron como el peldaño indispensable para alcanzar, posteriormente, otros curatos donde pudieran desarrollar una acción pastoral o misionera más satisfactoria.

c) Contribuyen también a tales etapas sin información los viajes del párroco, en algunas ocasiones, al Arzobispado de La Plata para cumplir los trámites de "visita", ${ }^{3}$ para atender a los quebrantos de su salud o a sus gestiones personales, o bien (con mayor incidencia probablemente) sus más o menos frecuentes desplazamientos desde el pueblo matriz o iglesia parroquial a los poblados anexos. Claro está que, en muchas oportunidades, se aprecia en los libros parroquiales un efectivo y acumulado registro de inscripciones sacramentales (bautismos, matrimonios, exequias funerarias) correspondientes a actos o hechos sucedidos en un lugar determinado durante las ausencias del sacerdote (nacimientos, iniciación de vida marital, defunciones), pero resulta evidente, a través del examen cuidadoso de los libros, que muchos de tales acontecimientos, en diversas ocasiones, quedaron sin registro ni anotación.

d) Finalmente, también se comprueba irregularidad en el conjunto de los datos que se consignan en las inscripciones. Pese a las instrucciones que, con detalle y cierta insistencia, se dan y consignan en las "visitas", sin embargo, párrocos en propiedad ("cura propio"), sustitutos ad inter, o tenientes de curas, colaboradores licentia parroci, manifiestan en sus respectivas inscripciones diferencias de criterio o de procedimiento; a veces, meticulosidad en el detalle; otras, descuidada e imprecisa redacción.

3. Como un pequeño avance de datos demográficos más fácilmente obtenibles por el momento

3 Contrariamente a lo ocurrido en el transcurso del siglo XVII, durante el cual los visitadores eclesiásticos, delegados del Arzobispo de La Plata, inspeccionaban personalmente las tierras atacameñas ( $C f r$. Casassas Cantú, José María: "La Región Atacameña en el siglo XVII -tesis doctoral-, tomo I, pp. 157 a 163, edición provisional en Madrid, 1970; extracto, Barcelona, 1971; en prensa, edición revisada), durante el siglo XVIII la "visita" a inspección de los libros parroquiales se efectuó casi siempre en la misma arquidiócesis de La Plata, según aparece en los propios libros parroquiales, cuyo detalle se establece en la siguiente nota. sobre la región atacameña, limitamos el presente estudio al siglo XVIII basados en la información que nos proporcionan los libros sacramentales de los dos curatos o doctrinas que entonces existían en la región, a saber: el de San Francisco de Asís, de Chiu Chiu, conocido también como Atacama la Baja o la Chica, cuya jurisdicción comprendía toda la parte septentrional atacameña, o sea, los anexos precordilleranos de Calama, Aiquina y Caspana (con Lasana también, en el siglo XVII), y la viceparroquia de Cobija, en el litoral, y el de San Pedro de Atacama (Atacama la Alta o la Grande), con sus anexos meridionales de Toconao, Socaire y Peine, en la zona del Salar, y ya abarcando la Puna, los de lngaguasi y Susques. Aunque el conjunto de estos datos demográficos resulte pobre e insuficiente para llegar a conclusiones satisfactorias en el terreno científico, hemos creído conveniente dejarlos establecidos mediante este trabajo por el valor que puedan tener en sí y como base o complemento de posibles investigaciones futuras; y además no podemos dejar de precaver y ser prudentemente previsores, en la medida de nuestras escasas posibilidades, ante la eventual pérdida o destrucción parcial o total de estos libros parroquiales, ${ }^{4}$ generalmente conservados en condiciones de muy escasa seguridad.

4. De tales libros parroquiales, consideramos tan sólo el número de personas a quienes afectan los sacramentos administrados, y establecemos, a tal efecto, los correspondientes cuadros numéricos de personas bautizadas, casadas y enterradas, según

4 Los libros o registros parroquiales utilizados para este trabajo son los que se detallan a continuación. De Chiu Chiu o Atacama la Baja: 2. "De Bautismos", 3. "Libro $3^{\circ}$ de Bautismos de 1765 hasta 1822"; 13. "De Casamientos"; 14. "Libro $2^{\circ}$ Matrimonios"; 18. ("Libro de Entierros"); y 19. "Libro de Entierros"; excepcionalmente, como ya se indica expresamente en la ocasión oportuna, algún dato se ha obtenido del libro 1. "Libro de varias ojas - 1611-1698". De San Pedro de Atacama o Atacama la Alta: 1. "Libro primero de Bautismos, años 1737-1784"; 2. "Segundo Libro de Bautismos (1767-1791)"; 3. "Libro tercero de bautismos (1791-1808)"; 17. "Matrimonios - Libro I - 1763-1808"; 23. "Defunciones - Libro I - 1763-1791"; y 24. "Defunciones - Libro II 1767-1791 y 1791-1814". Los números y denominaciones consignados son los que figuran en mi trabajo: Inventario de los Archivos del Arzobispado de Antofagasta, de la Prelatura de Calama y de sus respectivas parroquias, en Anales de la Universidad del Norte, $N^{\circ} 8,1970$, pp. 141 a 303 (concretamente para Chiu Chiu, pp. 256 a 268; y para San Pedro de Atacama, pp. 276 a 284). 
las inscripciones registradas durante el siglo XVIII y que se han conservado hasta nuestros días. Hemos de aclarar que la atribución de un número de personas a una determinada localidad no implica necesariamente que todas aquellas personas tuvieran residencia normal en tal núcleo habitacional. De hecho, en algunos casos, y lo indicamos a manera de ejemplo, en las inscripciones un bautizado o casado en la parroquia de Chiu Chiu se menciona como natural de Calama o de Caspana, o bien, un sacramento registrado en San Pedro de Atacama afecta a un oriundo de Toconao o de Peine, pero ciertamente las más de las veces no se aclara si habitualmente aquellas personas seguían residiendo en el pueblo de su naturaleza o si era accidental o permanente su presencia en el lugar de administración del sacramento. Por ello, como medida general, y en la duda, se ha seguido el criterio de anotar cada persona en el lugar -iglesia matriz, viceparroquia o capilla anexa- que aparece expresado en la inscripción sacramental. Igual proceder se ha aplicado en el caso de las defunciones o entierros, aunque, naturalmente, ofrecen menores motivos de duda, por lo general.

5. Bautismos. En los cuadros I y II se detallan a continuación numéricamente los bautismos realizados año tras año, del 1701 al 1800, en las dos parroquias antes mencionadas y sus respectivos anexos, separadas las columnas relativas a varones de las que se refieren a las mujeres, especificando así para cada sexo el número de personas bautizadas en cada uno de los núcleos poblaciones de la región.

Por las razones señaladas en el punto 2 de este trabajo, no es aventurado llegar a la conclusión de que realmente fue mucho mayor el número efectivo de nacimientos en cada lugar y en el conjunto del territorio atacameño, pues, aparte de los vacíos cronológicos que en dicho punto son aludidos, la mortalidad infantil era muy grande en los primeros días o semanas del nacimiento por razones obvias. Con frecuencia extraordinaria, quizás superior a un 50\%, en las inscripciones de bautismo figuran anotaciones tales como: "puse óleo y crisma a ............. a quien en caso de necesidad había echado el agua...." una persona cualquiera de la localidad, precisamente por tal "caso de necesidad", o sea, de evidente grave peligro de muerte. ${ }^{5}$ En consecuencia, podemos suponer, aunque no tengamos la base documental contabilizable en un rigorismo científico, el gran número de infantes de uno y otro sexo que nacieron y murieron sin que quedase constancia alguna de su breve existencia.

Expuestas estas consideraciones generales sobre los bautismos en el conjunto de la región atacameña, conviene formular algunas observaciones o aclaraciones en relación con las fuentes documentales que sirven de base a los cuadros I y II.

En el cuadro I los datos hasta 1765 corresponden al libro 2 "De Bautismos" de la parroquia de San Francisco de Asís, de Chiu Chiu; y del 1765 al 1800 se han obtenido del "Libro $3^{\circ}$ de Bautismos...", de la misma parroquia. Sin embargo, entre los bautismos relativos a Cobija en el año 1744 aparecen contabilizados dos de hombres y cuatro de mujeres que figuran intercalados en un libro que no correspondía, del siglo XVII, o sea en la hoja 78 vuelta del "Libro de varias ojas 1611-1698”, de Chiu Chiu.

En el cuadro II pertenecen al "Libro primero de Bautismos..." de la parroquia de San Pedro de Atacama los datos hasta 1783, los cuales se inician tan sólo en el año 1737, pues se han extraviado los libros o registros anteriores correspondientes al siglo XVIII y aun a los años de los siglos XVII y XVI, ya que existe constancia de que dicho curato o doctrina existía ya en $1557^{6}$; de 1784 a 1789, y excepcionalmente desde 1767 en lo que atañe al asiento o mineral de Ntra. Sra. de Loreto de Ingaguasi, los datos emanan del "Segundo Libro de Bautismos"; y de 1792 en adelante se han obtenido del "Libro tercero de Bautismos". Debe hacerse constar, también, que en la columna correspondiente a Socaire (abrev.: Soc.) figuran los bautizados en dicha capilla pública quienes, normalmente, procedían de Socaire o de Peine. A pesar de las dos capillas (la del pueblo nuevo y la vieja en medio de las ruinas del pueblo preincásico) de que nos habla Roberto Montandón $^{7}$, no existe ninguna constancia de

5 Entre innumerables casos que podrían ser citados, véase por vía de ejemplo: 2. "De Bautismos", hoja 69, segunda inscripción, de la parroquia de Chiu Chiu.

6 Cfr. Casassas Cantú, José María: Noticias sobre la Iglesia Católica en la provincia de Antofagasta, Santiago de Chile, Universidad del Norte; Editorial Orbe, 1968, pp. 14 a 17.

7 Cfr. Montandón, Roberto: Iglesias y Capillas coloniales en el Desierto de Atacama, Santiago de Chile; Cuadernos del Consejo de Monumentos Nacionales, sin año. 
Cuadro I. Bautismos en Chiu Chiu y sus anexos.

Abreviaturas: ChCh: Chiu Chiu - Aiq: Aiquina - Cal: Calama - Casp: Caspana - Cob: Cobija

\begin{tabular}{|c|c|c|c|c|c|c|c|c|c|c|c|c|c|}
\hline Año & Chch & Aiq & $\begin{array}{c}\text { Hombres } \\
\text { Cal }\end{array}$ & Casp & Cob & $\begin{array}{l}\text { sub- } \\
\text { total }\end{array}$ & Chch & Aiq & $\begin{array}{c}\text { Mujeres } \\
\text { Cal }\end{array}$ & Casp & Cob & $\begin{array}{l}\text { sub- } \\
\text { total }\end{array}$ & $\begin{array}{c}\text { Total } \\
\text { bautizados }\end{array}$ \\
\hline 1701 & 2 & - & - & 1 & 6 & 9 & 3 & - & - & 2 & 4 & 9 & 18 \\
\hline 1702 & 3 & 2 & - & 1 & 5 & 11 & 6 & - & - & 2 & 4 & 12 & 23 \\
\hline 1703 & 7 & 1 & - & 2 & 6 & 16 & 12 & - & - & 2 & 4 & 18 & 34 \\
\hline 1704 & 5 & - & 1 & 3 & 4 & 13 & 3 & - & - & 2 & 2 & 7 & 20 \\
\hline 1705 & 4 & - & - & - & 9 & 13 & 8 & 1 & - & - & 1 & 10 & 23 \\
\hline 1706 & 5 & 1 & - & 1 & 8 & 15 & 8 & - & - & 2 & 6 & 16 & 31 \\
\hline 1707 & 2 & - & - & 2 & 2 & 6 & 6 & - & - & 5 & 6 & 17 & 23 \\
\hline 1708 & 9 & - & - & 2 & 5 & 16 & 9 & 1 & - & - & 6 & 16 & 32 \\
\hline 1709 & 1 & - & - & 2 & - & 3 & 1 & - & - & 5 & - & 6 & 9 \\
\hline 1710 & 5 & - & - & 1 & 13 & 19 & 4 & - & - & 1 & 7 & 12 & 31 \\
\hline 1711 & 3 & - & - & - & 1 & 4 & 1 & - & - & - & 2 & 3 & 7 \\
\hline 1712 & 2 & - & - & - & 10 & 12 & 1 & - & - & 2 & 3 & 6 & 18 \\
\hline 1713 & 1 & - & 3 & 2 & 3 & 9 & 1 & - & 2 & 2 & 12 & 17 & 26 \\
\hline 1714 & - & - & 2 & 7 & - & 9 & 5 & - & - & 4 & - & 9 & 18 \\
\hline 1715 & 8 & - & - & - & 1 & 9 & 11 & - & - & 3 & 4 & 18 & 27 \\
\hline 1716 & 6 & - & - & - & - & 6 & 4 & - & - & - & - & 4 & 10 \\
\hline 1717 & 5 & - & - & - & - & 5 & 4 & - & - & - & 2 & 6 & 11 \\
\hline 1718 & 8 & - & - & - & 3 & 11 & 8 & - & - & - & 2 & 10 & 21 \\
\hline 1719 & 6 & - & - & - & 1 & 7 & 3 & - & - & - & 1 & 4 & 11 \\
\hline 1720 & 1 & - & - & - & - & 1 & - & - & - & - & - & 0 & 1 \\
\hline 1721 & 9 & - & - & 1 & 3 & 13 & 8 & - & - & 1 & 1 & 10 & 23 \\
\hline 1722 & 7 & - & - & - & - & 7 & 5 & - & - & - & - & 5 & 12 \\
\hline 1723 & 3 & - & - & - & - & 3 & 8 & - & - & - & - & 8 & 11 \\
\hline 1724 & 5 & - & - & - & - & 5 & 2 & - & - & - & - & 2 & 7 \\
\hline 1725 & 8 & - & - & - & 6 & 14 & 8 & - & - & - & 1 & 9 & 23 \\
\hline 1726 & 10 & - & - & - & 3 & 13 & 8 & - & - & - & 4 & 12 & 25 \\
\hline 1727 & 4 & - & - & - & 1 & 5 & 4 & - & - & - & 5 & 9 & 14 \\
\hline 1728 & 4 & - & - & - & 2 & 6 & 12 & - & - & 1 & 1 & 14 & 20 \\
\hline 1729 & 13 & - & - & - & 5 & 18 & 11 & - & - & 1 & 4 & 16 & 34 \\
\hline 1730 & 3 & - & - & - & 3 & 6 & 1 & - & - & - & 2 & 3 & 9 \\
\hline 1731 & 7 & - & - & 2 & - & 9 & 5 & - & - & 1 & - & 6 & 15 \\
\hline 1732 & 4 & 1 & - & - & - & 5 & 5 & - & - & - & - & 5 & 10 \\
\hline 1733 & 10 & - & - & - & - & 10 & 13 & - & - & - & - & 13 & 23 \\
\hline 1734 & 4 & - & - & - & - & 4 & 3 & - & - & 1 & - & 4 & 8 \\
\hline 1735 & 3 & 2 & - & 1 & 3 & 9 & 3 & - & - & - & 2 & 5 & 14 \\
\hline 1736 & 7 & - & - & 1 & 5 & 13 & 7 & - & - & 3 & 1 & 11 & 24 \\
\hline 1737 & 10 & - & - & 1 & 4 & 15 & 10 & - & - & 1 & 3 & 14 & 29 \\
\hline 1738 & 2 & - & - & 1 & 4 & 7 & 8 & - & - & 2 & 3 & 13 & 20 \\
\hline 1739 & 6 & - & - & - & 1 & 7 & 11 & - & - & - & 3 & 14 & 21 \\
\hline 1740 & 14 & - & - & - & - & 14 & 13 & - & - & - & - & 13 & 27 \\
\hline 1741 & 5 & - & - & 1 & - & 6 & 2 & - & - & - & - & 2 & 8 \\
\hline 1742 & 9 & - & - & - & 2 & 11 & 12 & - & 2 & - & 1 & 15 & 26 \\
\hline 1743 & 15 & - & - & - & 3 & 18 & 11 & - & - & - & - & 11 & 29 \\
\hline 1744 & 5 & - & - & 1 & 5 & 11 & 9 & - & - & 5 & 7 & 21 & 32 \\
\hline 1745 & 8 & - & - & - & 2 & 10 & 15 & - & - & - & - & 15 & 25 \\
\hline 1746 & 5 & 2 & 4 & - & - & 11 & 5 & 2 & 1 & - & - & 8 & 19 \\
\hline 1747 & 1 & - & - & - & 2 & 3 & 2 & 1 & - & - & 3 & 6 & 9 \\
\hline 1748 & 5 & - & - & - & 4 & 9 & 4 & 1 & - & - & 3 & 8 & 17 \\
\hline 1749 & 6 & - & - & - & 1 & 7 & 2 & 1 & - & 2 & 2 & 7 & 14 \\
\hline 1750 & 3 & 2 & - & 3 & - & 8 & 5 & 1 & - & 1 & - & 7 & 15 \\
\hline 1751 & 7 & - & - & - & 1 & 8 & 2 & - & - & - & - & 2 & 10 \\
\hline 1752 & 5 & - & - & 2 & - & 7 & 10 & 1 & - & 1 & 1 & 13 & 20 \\
\hline 1753 & 5 & 2 & - & - & - & 7 & 10 & 1 & - & 1 & - & 12 & 19 \\
\hline 1754 & 8 & 1 & - & - & - & 9 & 10 & - & - & - & - & 10 & 19 \\
\hline
\end{tabular}


Cuadro I. (Continuación)

\begin{tabular}{|c|c|c|c|c|c|c|c|c|c|c|c|c|c|}
\hline Año & Chch & Aiq & $\begin{array}{c}\text { Hombres } \\
\text { Cal }\end{array}$ & Casp & Cob & $\begin{array}{l}\text { sub- } \\
\text { total }\end{array}$ & Chch & Aiq & $\begin{array}{c}\text { Mujeres } \\
\text { Cal }\end{array}$ & Casp & Cob & $\begin{array}{l}\text { sub- } \\
\text { total }\end{array}$ & $\begin{array}{c}\text { Total } \\
\text { bautizados }\end{array}$ \\
\hline 1755 & 10 & - & 1 & - & 3 & 14 & 9 & - & 2 & - & 1 & 12 & 26 \\
\hline 1756 & 5 & - & - & - & - & 5 & 4 & 1 & - & - & - & 5 & 10 \\
\hline 1757 & 6 & - & 3 & 1 & - & 10 & 10 & 1 & - & 5 & - & 16 & 26 \\
\hline 1758 & 10 & 1 & 3 & - & - & 14 & 4 & - & 2 & - & - & 6 & 20 \\
\hline 1759 & 5 & - & 1 & 3 & - & 9 & 2 & - & 2 & 1 & - & 5 & 14 \\
\hline 1760 & - & - & 1 & - & - & 1 & - & - & 3 & - & - & 3 & 4 \\
\hline 1761 & 9 & - & - & - & - & 9 & 8 & - & - & - & - & 8 & 17 \\
\hline 1762 & 2 & - & 2 & - & - & 4 & 5 & - & 4 & - & - & 9 & 13 \\
\hline 1763 & - & - & - & - & - & 0 & - & - & - & - & - & 0 & 0 \\
\hline 1764 & 7 & 4 & 2 & - & - & 13 & 3 & 6 & 3 & - & - & 12 & 25 \\
\hline 1765 & 2 & - & 1 & 3 & - & 6 & 1 & - & 1 & 1 & - & 3 & 9 \\
\hline 1766 & 11 & 1 & 2 & - & - & 14 & 9 & - & 3 & - & - & 12 & 26 \\
\hline 1767 & 14 & - & 3 & - & 1 & 18 & 14 & 1 & 1 & - & 2 & 18 & 36 \\
\hline 1768 & 7 & - & 2 & - & 7 & 16 & 10 & 1 & - & 2 & 9 & 22 & 38 \\
\hline 1769 & 9 & 4 & 2 & 3 & 5 & 23 & 12 & - & 5 & 2 & 1 & 20 & 43 \\
\hline 1770 & 11 & 1 & 2 & 2 & 3 & 19 & 7 & 2 & 2 & - & 1 & 12 & 31 \\
\hline 1771 & 9 & 1 & - & 1 & 1 & 12 & 6 & - & 4 & 1 & - & 11 & 23 \\
\hline 1772 & 13 & 1 & 3 & 4 & 4 & 25 & 9 & - & - & 2 & 3 & 14 & 39 \\
\hline 1773 & 8 & 2 & 1 & 3 & 2 & 16 & 5 & - & - & 1 & 7 & 13 & 29 \\
\hline 1774 & 18 & 1 & 3 & - & 2 & 24 & 6 & - & - & 4 & 3 & 13 & 37 \\
\hline 1775 & 9 & - & 2 & 3 & 4 & 18 & 4 & 1 & 5 & 1 & 4 & 15 & 33 \\
\hline 1776 & 9 & 2 & 3 & - & 2 & 16 & 4 & 3 & 3 & 1 & 1 & 12 & 28 \\
\hline 1777 & 10 & - & 5 & 2 & - & 17 & - & 3 & 1 & 2 & - & 6 & 23 \\
\hline 1778 & 8 & 2 & 2 & 5 & 4 & 21 & 4 & 1 & 1 & 1 & 1 & 8 & 29 \\
\hline 1779 & 12 & - & 2 & 4 & - & 18 & 5 & 1 & 2 & 2 & 1 & 11 & 29 \\
\hline 1780 & 11 & 2 & 3 & 1 & 7 & 24 & 8 & 2 & - & 6 & 3 & 19 & 43 \\
\hline 1781 & 8 & 2 & 3 & 1 & - & 14 & 4 & - & 1 & - & 1 & 6 & 20 \\
\hline 1782 & 12 & - & 3 & - & 4 & 19 & 12 & 2 & 2 & 3 & 4 & 23 & 42 \\
\hline 1783 & 9 & - & 4 & 1 & - & 14 & 2 & - & 4 & 3 & - & 9 & 23 \\
\hline 1784 & 17 & 1 & 5 & 5 & 3 & 31 & 14 & 1 & 3 & - & 3 & 21 & 52 \\
\hline 1785 & 8 & - & 3 & - & - & 11 & 12 & - & 1 & - & 1 & 14 & 25 \\
\hline 1786 & 7 & - & 1 & 3 & 2 & 13 & 14 & - & - & 3 & 2 & 19 & 32 \\
\hline 1787 & 13 & - & 4 & - & 2 & 19 & 13 & 1 & 5 & - & 3 & 22 & 41 \\
\hline 1788 & 8 & 1 & 1 & 2 & - & 12 & 11 & - & 4 & 1 & - & 16 & 28 \\
\hline 1789 & 5 & 1 & 2 & 3 & - & 11 & 3 & 1 & 2 & 1 & - & 7 & 18 \\
\hline 1790 & 9 & 2 & 2 & 1 & 2 & 16 & 10 & 2 & - & 3 & 1 & 16 & 32 \\
\hline 1791 & 11 & - & 8 & 7 & - & 26 & 13 & 1 & 3 & 4 & - & 21 & 47 \\
\hline 1792 & 13 & 2 & 9 & 2 & 3 & 29 & 10 & 1 & 2 & - & 2 & 15 & 44 \\
\hline 1793 & 7 & 1 & 5 & - & - & 13 & 14 & 1 & 6 & - & - & 21 & 34 \\
\hline 1794 & 9 & 3 & 2 & 4 & 1 & 19 & 16 & 4 & 2 & 2 & 3 & 27 & 46 \\
\hline 1795 & 12 & - & 4 & 1 & - & 17 & 9 & - & 3 & - & - & 12 & 29 \\
\hline 1796 & - & - & 1 & - & - & 1 & - & - & - & - & - & 0 & 1 \\
\hline 1797 & 5 & - & 4 & 3 & 3 & 15 & 12 & - & 3 & - & 1 & 16 & 31 \\
\hline 1798 & 9 & - & 9 & - & - & 18 & - & - & 3 & - & - & 3 & 21 \\
\hline 1799 & 27 & - & - & - & 3 & 30 & 15 & - & - & - & 11 & 26 & 56 \\
\hline 1800 & 14 & 2 & 5 & - & 1 & 22 & 8 & 2 & 2 & - & 1 & 13 & 35 \\
\hline
\end{tabular}


Cuadro II. Bautismos en San Pedro de Atacama y sus anexos.

Abreviaturas: SPAt: S. Pedro de Atacama - Ing: Ingaguasi - Soc: Socaire-Peine - Sus: Susques - Toc: Toconao

\begin{tabular}{|c|c|c|c|c|c|c|c|c|c|c|c|c|c|}
\hline Año & SPAt & Ing & $\begin{array}{l}\text { Hombres } \\
\text { Soc }\end{array}$ & Sus & Toc & $\begin{array}{l}\text { sub- } \\
\text { total }\end{array}$ & SPAt & Ing & $\begin{array}{l}\text { Mujeres } \\
\text { Soc }\end{array}$ & Sus & Toc & $\begin{array}{l}\text { sub- } \\
\text { total }\end{array}$ & $\begin{array}{c}\text { Total } \\
\text { bautizados }\end{array}$ \\
\hline 1715 & 1 & - & - & - & - & 1 & - & - & - & - & - & 0 & 1 \\
\hline 1737 & 16 & - & - & - & 1 & 17 & 7 & - & - & - & 2 & 9 & 26 \\
\hline 1738 & 32 & - & - & - & 4 & 36 & 29 & - & - & - & 6 & 35 & 71 \\
\hline 1739 & 27 & - & - & - & 4 & 31 & 24 & - & 1 & - & 6 & 31 & 62 \\
\hline 1740 & 19 & - & 2 & - & 5 & 26 & 16 & - & 1 & - & 3 & 20 & 46 \\
\hline 1741 & 24 & - & 1 & - & 1 & 26 & 24 & - & 3 & - & 4 & 31 & 57 \\
\hline 1742 & 8 & - & - & - & 5 & 13 & 21 & - & 3 & - & 3 & 27 & 40 \\
\hline 1743 & 33 & - & 3 & - & 7 & 43 & 40 & - & - & - & 7 & 47 & 90 \\
\hline 1744 & 19 & - & 4 & - & 2 & 25 & 22 & - & 1 & - & 2 & 25 & 50 \\
\hline 1745 & 27 & - & 1 & - & 3 & 31 & 32 & - & 1 & - & 1 & 34 & 65 \\
\hline 1746 & 22 & - & 3 & - & 4 & 29 & 26 & - & 2 & - & 3 & 31 & 60 \\
\hline 1747 & 15 & - & - & - & 7 & 22 & 33 & - & - & - & 2 & 35 & 57 \\
\hline 1748 & 26 & - & 2 & - & 6 & 34 & 23 & - & 2 & - & 3 & 28 & 62 \\
\hline 1749 & 29 & - & 1 & - & 5 & 35 & 39 & - & 2 & - & 2 & 43 & 78 \\
\hline 1750 & 29 & - & 1 & - & 5 & 35 & 34 & - & 1 & - & 2 & 37 & 72 \\
\hline 1751 & 35 & - & 3 & - & 3 & 41 & 34 & - & 1 & - & 5 & 40 & 81 \\
\hline 1752 & 32 & - & 2 & 1 & 6 & 41 & 26 & - & 6 & - & 5 & 37 & 78 \\
\hline 1753 & 30 & - & 6 & 8 & 4 & 48 & 32 & - & 4 & 7 & 2 & 45 & 93 \\
\hline 1754 & 29 & - & 2 & - & 7 & 38 & 27 & - & 2 & - & 2 & 31 & 69 \\
\hline 1755 & 33 & - & 2 & - & 4 & 39 & 32 & - & 3 & - & 6 & 41 & 80 \\
\hline 1756 & 31 & - & 1 & 4 & 3 & 39 & 38 & - & 3 & 15 & 3 & 59 & 98 \\
\hline 1757 & 17 & - & - & - & 2 & 19 & 25 & - & - & - & 4 & 29 & 48 \\
\hline 1758 & 46 & - & 6 & - & 5 & 57 & 24 & - & 4 & - & 5 & 33 & 90 \\
\hline 1759 & 28 & - & - & 1 & 5 & 34 & 24 & - & 2 & - & 4 & 30 & 64 \\
\hline 1760 & 6 & - & - & - & 1 & 7 & 5 & - & - & - & 1 & 6 & 13 \\
\hline 1761 & 28 & - & 5 & - & 2 & 35 & 22 & - & 6 & - & 11 & 39 & 74 \\
\hline 1762 & 15 & - & - & - & 19 & 34 & 22 & - & 1 & 1 & 12 & 36 & 70 \\
\hline 1763 & 34 & - & - & 2 & 17 & 53 & 56 & - & 3 & 5 & 8 & 72 & 125 \\
\hline 1764 & 30 & - & 1 & - & 6 & 37 & 41 & - & 2 & 4 & 10 & 57 & 94 \\
\hline 1765 & 29 & - & - & 1 & 10 & 40 & 43 & - & 2 & - & 9 & 54 & 94 \\
\hline 1766 & 28 & 4 & - & 4 & 3 & 39 & 38 & 8 & - & 8 & 2 & 56 & 95 \\
\hline 1767 & 30 & 3 & - & 1 & 7 & 41 & 30 & 6 & 3 & 2 & 4 & 45 & 86 \\
\hline 1768 & 20 & 6 & - & 8 & 5 & 39 & 27 & 2 & - & 8 & 5 & 42 & 81 \\
\hline 1769 & 37 & - & - & 6 & 5 & 48 & 29 & 1 & 1 & 11 & 7 & 49 & 97 \\
\hline 1770 & 23 & 3 & 3 & 7 & 2 & 38 & 39 & 1 & 2 & 2 & 6 & 50 & 88 \\
\hline 1771 & 18 & 5 & 1 & - & 4 & 28 & 23 & 5 & - & - & 5 & 33 & 61 \\
\hline 1772 & 34 & 5 & 5 & 8 & 1 & 53 & 33 & 3 & 4 & 8 & 8 & 56 & 109 \\
\hline 1773 & 31 & - & - & 6 & 1 & 38 & 26 & 5 & - & 9 & 5 & 45 & 83 \\
\hline 1774 & 23 & - & 2 & 6 & 6 & 37 & 28 & - & 4 & 4 & 8 & 44 & 81 \\
\hline 1775 & 39 & 1 & 2 & - & 3 & 45 & 29 & 4 & 3 & 5 & 1 & 42 & 87 \\
\hline 1776 & 31 & 3 & 1 & 7 & 3 & 45 & 29 & 1 & - & 6 & 7 & 43 & 88 \\
\hline 1777 & 21 & 2 & - & 8 & 2 & 33 & 29 & 1 & - & 6. & 6 & 42 & 75 \\
\hline 1778 & 23 & 6 & 1 & 6 & 4 & 40 & 36 & 4 & 3 & 2 & 4 & 49 & 89 \\
\hline 1779 & 27 & 2 & 1 & 4 & 5 & 39 & 29 & 1 & 1 & 5 & 6 & 42 & 81 \\
\hline 1780 & 26 & 1 & 2 & 6 & 6 & 41 & 34 & 1 & 1 & 5 & 3 & 44 & 85 \\
\hline 1781 & 26 & 15 & - & 3 & 6 & 50 & 36 & 5 & - & 4 & 6 & 51 & 101 \\
\hline 1782 & 39 & 1 & 2 & 8 & 2 & 52 & 38 & 5 & - & 7 & 6 & 56 & 108 \\
\hline 1783 & 31 & 4 & 2 & 7 & 6 & 50 & 28 & 8 & 3 & 5 & 4 & 48 & 98 \\
\hline 1784 & 32 & - & 3 & 7 & 8 & 50 & 30 & - & 3 & 3 & 6 & 42 & 92 \\
\hline 1785 & 27 & - & - & 8 & 6 & 41 & 35 & - & 2 & 8 & 3 & 48 & 89 \\
\hline 1786 & 26 & 6 & 2 & 9 & 3 & 46 & 34 & 9 & 2 & 12 & 6 & 63 & 109 \\
\hline 1787 & 31 & - & 2 & 5 & 2 & 40 & 34 & - & 6 & 14 & 4 & 58 & 98 \\
\hline 1788 & 10 & 1 & - & 13 & 11 & 35 & 11 & 3 & - & 3 & 7 & 24 & 59 \\
\hline 1789 & 16 & - & 3 & 4 & - & 23 & 13 & - & 1 & 4 & - & 18 & 41 \\
\hline 1790 & - & - & - & - & - & 0 & - & - & - & - & - & 0 & 0 \\
\hline 1791 & 4 & - & 1 & - & 2 & 7 & 5 & - & - & - & 1 & 6 & 13 \\
\hline 1792 & 29 & 3 & 2 & 7 & 7 & 48 & 35 & 3 & 5 & 8 & 9 & 60 & 108 \\
\hline 1793 & 49 & - & 2 & 4 & 9 & 64 & 30 & - & 2 & 3 & 8 & 43 & 107 \\
\hline 1794 & 41 & - & 1 & 8 & 10 & 60 & 41 & - & 3 & 13 & 4 & 61 & 121 \\
\hline 1795 & 35 & - & 4 & 3 & 1 & 43 & 30 & - & - & 1 & 3 & 34 & 77 \\
\hline 1796 & 24 & - & - & 5 & 6 & 35 & 22 & - & 4 & 1 & 9 & 36 & 71 \\
\hline 1797 & 49 & - & - & 9 & 3 & 61 & 35 & - & 2 & 8 & 6 & 51 & 112 \\
\hline 1798 & 38 & - & 2 & 1 & 7 & 48 & 30 & - & 3 & 3 & 10 & 46 & 94 \\
\hline 1799 & 28 & - & - & 1 & 6 & 35 & 38 & - & 1 & - & 4 & 43 & 78 \\
\hline 1800 & 42 & - & 1 & 13 & 5 & 61 & 30 & 1 & 5 & 9 & 12 & 57 & 118 \\
\hline
\end{tabular}


inscripciones sacramentales efectuadas precisamente en Peine durante los años que nos ocupan.

6. Confirmaciones. En el libro 2 "De Bautismos" de Chiu Chiu, entre las hojas 41 vuelta y 42, figuran intercalados unos cuadernillos (cosidos en el conjunto del libro), pero sin numerar, con la relación "de la gente de Atacama la alta y baxa" que fue confirmada en Chiu Chiu entre los días 20 y 27 de mayo de 1731 por el Obispo de Santiago, electo del Arzobispado de La Plata. Según dicha relación nominativa, en Chiu Chiu fueron confirmadas en aquella oportunidad 405 personas (206 hombres y 199 mujeres) pero no se expresa para ninguna de ellas lugar de naturaleza o residencia sino tan sólo la declaración, ya antedicha, de comprender "gente" de ambos curatos: Atacama la Alta y Atacama la Baja, o sea, probablemente de toda la región, en su zona interior. A continuación de tal relación, figura la correspondiente a las confirmaciones administradas en Cobija, entre los días 10 al 13 de mayo de 1731 . Se refiere a 135 personas, de las cuales 77 eran hombres y 58 mujeres. Debe tenerse presente que, en ambas relaciones (que en conjunto totalizan 540 personas: 283 hombres y 257 mujeres), además de los confirmados figuran los nombres de los respectivos padrinos; pero esto no significaría duplicación del número de personas ya que, en muchos casos, los padrinos eran integrantes eclesiásticos o civiles del séquito episcopal y, además, tanto en tales casos como cuando, por sus nombres, puede suponerse que los padrinos eran atacameños, una misma persona apadrinaba a varios confirmados.

En ningún otro libro parroquial hemos encontrado otras relaciones o detalles de confirmaciones durante el siglo XVIII.

7. Confesiones. Tan sólo en el "Libro de varias ojas - 1611-1698" de Chiu Chiu, hoja 56 vuelta, aparece una relación de confesiones. En ella, que corresponde con toda probabilidad al año 1743, se detallan los nombres de 20 hombres y 50 mujeres, pero nada indica que sean precisamente residentes de Chiu Chiu o de cualquiera otra localidad específica, ni en todo ni en parte.

8. Matrimonios. Su detalle numérico nos lo proporcionan a continuación los cuadros III y IV.

Por la índole de este sacramento, ambos cuadros no se refieren directamente al número de hom- bres o mujeres sino que contabilizan los matrimonios registrados.

Los datos del cuadro III proceden del libro "De Casamientos" y del "Libro $2^{\circ}$ Matrimonios", ambos de la parroquia de Chiu Chiu. Y es de lamentar que por la pérdida de abundantes hojas del primero de los libros indicados no hayan podido ser registrados en el cuadro muchos matrimonios que, seguramente, se celebraron en la mayoría de los núcleos de población de la parte septentrional de la región atacameña, especialmente en Chiu Chiu y Cobija, durante las seis primeras décadas del siglo. Considero bastante más completo el detalle desde 1765 en adelante, obtenido del segundo libro.

Si bien no aporta ningún detalle nuevo a las cifras establecidas en dicho cuadro III, consideramos que sí permite formarse una mejor idea de la escasez de población en este territorio septentrional de Atacama, el hecho de hacer presente la existencia de una gran cantidad de solicitudes de dispensas matrimoniales motivadas por la casi general existencia de impedimentos derivados de cópulas ilícitas entre los presuntos contrayentes y parientes de grados muy próximos. ${ }^{8}$

En cuanto a la zona meridional de la región atacameña, los datos del cuadro IV corresponden al registro parroquial de San Pedro de Atacama "Matrimonios - Libro I - 1763-1808". No hay libro anterior sobre matrimonios y, por ello, no tenemos ninguna constancia de los matrimonios que se celebraron en el período 1701 al 1762, que hemos de suponer en cifras más o menos similares a las que se registran entre 1763 y 1788 . Y tampoco poseemos dato alguno después del año 1788 y hasta fin del siglo, pues a pesar de que la cubierta del libro indica claramente: "1763-1808", se han extraviado las hojas que pudieron existir después del inicio de la única inscripción de matrimonio en San Pedro de Atacama que nos queda

\footnotetext{
También a título de ejemplo muy expresivo, véase en Archivo de la Parroquia de Chiu Chiu: 14. "Libro $2^{\circ}$ Matrimonios", entre hojas 20 vuelta y $21 \ldots$ dispensa de impedimento por "cópula ilícita" con hermana de la contrayente, y otra con primahermana... "el hallarse preñada la nominada Rosa de efecto de la viciosa amistad en que hemos vivido, siendo como son estos parajes tan cortos de vecindario y que en ello no podremos efectuar casarnos sin otros iguales impedimentos...".
} 
Cuadro III. Matrimonios en Chiu Chiu y sus anexos.

Abreviaturas: Chch: Chiu Chiu - Aiq: Aiquina - Cal: Calama - Casp: Caspana - Cob: Cobija

\begin{tabular}{|c|c|c|c|c|c|c|c|c|c|c|c|c|c|}
\hline Año & Chch & Aiq & Cal & Casp & Cob & Total & Año & Chch & Aiq & Cal & Casp & Cob & Total \\
\hline 1701 & - & - & 1 & 1 & - & 2 & 1756 & 1 & - & - & - & - & 1 \\
\hline 1702 & - & - & 1 & 2 & 1 & 4 & 1757 & 1 & - & 1 & - & - & 2 \\
\hline 1703 & - & - & - & - & 6 & 6 & 1758 & 4 & 1 & 4 & 2 & - & 11 \\
\hline 1704 & - & - & 1 & - & - & 1 & 1759 & 8 & - & - & - & - & 8 \\
\hline 1705 & - & - & - & - & 3 & 3 & 1760 & 9 & - & - & - & - & 9 \\
\hline 1706 & - & - & - & 1 & 1 & 2 & 1761 & 3 & - & - & - & - & 3 \\
\hline 1707 & - & - & - & - & 1 & 1 & 1762 & 5 & - & 1 & - & 4 & 10 \\
\hline 1708 & 1 & - & - & - & 4 & 5 & 1763 & 5 & - & - & - & - & 5 \\
\hline 1709 & - & - & - & - & 2 & 2 & 1764 & 3 & - & - & - & - & 3 \\
\hline 1710 & - & - & 2 & 1 & 2 & 5 & 1765 & 1 & - & - & - & - & 1 \\
\hline 1711 & - & - & 1 & - & 2 & 3 & 1766 & 11 & 2 & 3 & - & - & 16 \\
\hline 1712 & 3 & - & - & - & 5 & 8 & 1767 & 4 & 1 & - & - & - & 5 \\
\hline 1713 & 4 & - & 1 & - & - & 5 & 1768 & - & 1 & 1 & - & - & 2 \\
\hline 1714 & 5 & - & 1 & - & 1 & 7 & 1769 & 3 & 1 & - & - & - & 4 \\
\hline 1715 & 3 & - & - & - & 3 & 6 & 1770 & 5 & - & - & - & - & 5 \\
\hline 1716 & 5 & - & - & - & - & 5 & 1771 & - & - & 1 & - & 1 & 2 \\
\hline 1717 & 3 & - & 1 & - & - & 4 & 1772 & 5 & - & 3 & - & - & 8 \\
\hline 1722 & 1 & - & - & - & - & 1 & 1773 & 7 & 2 & 1 & - & 7 & 17 \\
\hline 1723 & - & - & - & - & - & 0 & 1774 & 12 & 2 & 3 & - & - & 17 \\
\hline 1724 & 2 & - & - & - & - & 2 & 1775 & 2 & 2 & 4 & - & 1 & 9 \\
\hline 1725 & 1 & - & - & - & - & 1 & 1776 & 1 & - & 2 & - & - & 3 \\
\hline 1726 & - & - & 1 & - & - & 1 & 1777 & - & - & - & - & - & 0 \\
\hline 1727 & - & - & - & - & 2 & 2 & 1778 & 11 & - & 1 & - & 1 & 13 \\
\hline 1728 & 1 & - & - & - & 5 & 6 & 1779 & 10 & - & 2 & - & - & 12 \\
\hline 1729 & - & - & 2 & - & - & 2 & 1780 & 4 & 1 & - & - & 1 & 6 \\
\hline 1734 & 3 & - & - & - & - & 3 & 1781 & 6 & - & 2 & - & - & 8 \\
\hline 1735 & 2 & - & - & - & - & 2 & 1782 & 7 & - & - & - & 1 & 8 \\
\hline 1738 & 2 & - & 1 & - & - & 3 & 1783 & 5 & - & - & - & - & 5 \\
\hline 1739 & 3 & - & 2 & - & - & 5 & 1784 & 2 & - & - & - & - & 2 \\
\hline 1740 & 1 & - & - & - & - & 1 & 1785 & 1 & - & - & - & - & 1 \\
\hline 1741 & 3 & - & 1 & - & - & 4 & 1786 & 4 & 1 & 1 & - & 1 & 7 \\
\hline 1742 & 2 & - & 2 & - & - & 4 & 1787 & 5 & 1 & 4 & - & - & 10 \\
\hline 1743 & 1 & - & - & - & - & 1 & 1788 & 5 & - & 4 & - & - & 9 \\
\hline 1744 & 3 & - & 2 & 1 & - & 6 & 1789 & 11 & 2 & - & - & - & 13 \\
\hline 1745 & 4 & - & - & - & - & 4 & 1790 & 2 & - & - & - & 2 & 4 \\
\hline 1746 & - & - & - & - & - & 0 & 1791 & 8 & 1 & 2 & - & - & 11 \\
\hline 1747 & 1 & - & - & - & - & 1 & 1792 & 9 & - & - & - & 2 & 11 \\
\hline 1748 & 2 & - & - & - & - & 2 & 1793 & 9 & - & - & - & - & 9 \\
\hline 1749 & 3 & - & - & - & - & 3 & 1794 & 9 & - & 2 & 1 & - & 12 \\
\hline 1750 & 4 & - & - & - & 2 & 6 & 1795 & 11 & - & 2 & 1 & - & 14 \\
\hline 1751 & 6 & - & - & - & 1 & 7 & 1796 & 9 & - & - & - & 1 & 10 \\
\hline 1752 & 4 & - & - & - & - & 4 & 1797 & 8 & 1 & 2 & - & 1 & 12 \\
\hline 1753 & 3 & - & - & 2 & - & 5 & 1798 & - & 1 & 2 & - & - & 3 \\
\hline 1754 & 5 & - & - & - & - & 5 & 1799 & 8 & - & 7 & 1 & 1 & 17 \\
\hline 1755 & 3 & - & - & 1 & - & 4 & 1800 & 5 & 2 & 5 & - & - & 12 \\
\hline
\end{tabular}

correspondiente al año 1788. Ni al principio ni al final del libro encontramos alguna nota explicatoria.

9. Defunciones. Con la misma metodología que ha sido empleada en los cuadros I y II, registramos las defunciones o entierros en los siguientes cuadros V y VI.
Los datos del cuadro $\mathrm{V}$ proceden de los dos registros 18 y 19 "Libros de Entierros", de Chiu Chiu. Lamentablemente en el primer libro faltan muchas hojas, especialmente al principio.

En el cuadro VI quedan detalladas las defunciones correspondientes a la zona meridional de la región atacameña, cuyos datos proceden de los 
Cuadro IV. Matrimonios en San Pedro de Atacama y sus anexos.

Abreviaturas: SPTt:, S. Pedro de Atacama - Ing: Ingaguasi Soc: Socaire-Peine - Sus: Susques - Toc: Toconao

\begin{tabular}{|rrrrrrr|}
\hline Año & SPAt & Ing & Soc & Sus & Toc & Total \\
\hline 1763 & 11 & - & - & - & - & 11 \\
1764 & 6 & - & 1 & 2 & - & 9 \\
1765 & 4 & - & 2 & 1 & - & 7 \\
1766 & 15 & - & - & - & 2 & 17 \\
1767 & 15 & - & - & 3 & 2 & 20 \\
1768 & 14 & - & 2 & 1 & 3 & 20 \\
1769 & 10 & - & - & - & 2 & 12 \\
1770 & 9 & - & 2 & 3 & 4 & 18 \\
1771 & 7 & - & - & - & 1 & 8 \\
1772 & 4 & - & - & 3 & 1 & 8 \\
1773 & 12 & - & - & 3 & 1 & 16 \\
1774 & 9 & - & - & 1 & 3 & 13 \\
1775 & 10 & - & - & - & 1 & 11 \\
1776 & 12 & - & - & 3 & 3 & 18 \\
1777 & 11 & - & 1 & 4 & 2 & 18 \\
1778 & 21 & - & 1 & 2 & - & 24 \\
1779 & 23 & - & - & 1 & - & 24 \\
1780 & 10 & - & 1 & 3 & - & 14 \\
1781 & 17 & - & - & 4 & - & 21 \\
1782 & 11 & - & 2 & 5 & 1 & 19 \\
1783 & 13 & - & - & 5 & 1 & 19 \\
1784 & 11 & - & - & 5 & 2 & 18 \\
1785 & 11 & - & - & 2 & 1 & 14 \\
1786 & 9 & - & - & 2 & - & 11 \\
1787 & 16 & - & - & 3 & - & 19 \\
1788 & 1 & - & - & - & - & 1 \\
1789 & - & - & - & - & - & 0 \\
1800 & - & - & - & - & - & 0 \\
& & & & & & \\
\hline & & & & & & \\
179 \\
179
\end{tabular}

libros 23 "Defunciones - Libro I...” y 24 "Defunciones - Libro II...". También aquí tropezamos con la dificultad de que el primer registro mencionado se inicia tan sólo en el año 1763 y, por lo tanto, carecemos de toda referencia sobre las defunciones ocurridas en los años anteriores.

Aparte de las cifras especificadas en ambos cuadros, creo de interés destacar los siguientes aspectos observados, sin que, por las razones ya indicadas al principiar estas páginas, haya cabido posibilidad, por ahora, de establecer estadísticas ni valores porcentuales: a) es alta la mortalidad infantil (escasos días o meses, muy cortos años); b) por el contrario, es notablemente frecuente la anotación de muertes ocurridas a edades muy avanzadas, especialmente para aquellos tiempos $\left(70,80,90,100\right.$ y aun 130 años). ${ }^{9}$
También debe señalarse la epidemia que asoló a Cobija en 1713, "en cuyo pueblo a fines del mes... de agosto entró una peste aguda de Virguelas y mal grabe...". Las consiguientes defunciones (16 hombres y 25 mujeres) fueron inscritas desde el día 1 al 19 de septiembre del mencionado año y se extienden desde la hoja 161 vuelta a la 164 vuelta del "Libro de Entierros" de Chiu Chiu antes mencionado. Las muchas hojas perdidas de tal registro, según se ha dicho, impiden saber si aquella epidemia afectó solamente a Cobija o si se extendió hacia el interior atacameño, aunque no parecería abonar esta segunda alternativa el número de defunciones inscritas dicho año en Calama y en Caspana, por ejemplo, más o menos similar al de otros años en tales localidades.

Aunque, a diferencia del caso al que acabo de referirme, no aparece ninguna declaración expresa sobre la existencia de otras epidemias, debe llamarnos la atención, sin embargo, el número de muertes que se registran en la zona septentrional en los años 1706, 1715, 1747, 1750, 1765, 1773, 1788, número muy crecido en relación con los fallecimientos registrados en los otros años, en general; lo que nos permite sospechar que en los años citados hubo también epidemias o incidencia de otras enfermedades o se produjeron otras circunstancias anormales. Lo mismo podemos decir -en cuanto a los datos del cuadro VI- para la zona meridional; también encontramos años en que el número de entierros sobrepasa al promedio que parece ser habitual en este territorio, tales como en 1764 y 1765 (que coinciden con defunciones muy numerosas en la zona septentrional), o los años 1775, 1777, 1783 y 1797.

10. Para un mejor ordenamiento y visualización de todos los datos demográficos obtenidos, creo conveniente ofrecerlos en conjunto en el siguiente cuadro VII, de acuerdo con los subtotales

9 Archivo de la Parroquia de Chiu Chiu: 23. ("Libro de Entierros"), hoja 124, segunda inscripción: "En el pueblo de Ntra. Señora de Ayquina, en diez y siete de mayo de mill setezientos y qta. hize las exequias sobre la sepultura de Juan Pasqual, que murió (aviendo rezevido el Sto. Sacrto. do penitenzia y euchuaristia) el día diez y ocho de marzo de dho. año murió de edad de ziento y treinta años, se le hizieron las exequias solennes y ofrezió a la fábrica dos pesos y para que conste lo firmé. Ldo. Juan Antonio Theran (rubricado)". 
JOSE MARIA CASASSAS CANTU

Cuadro V. Defunciones en Chiu Chiu y sus anexos.

Abreviaturas: Chch: Chiu Chiu - Aiq: Aiquina - Cal: Calama - Casp: Caspana

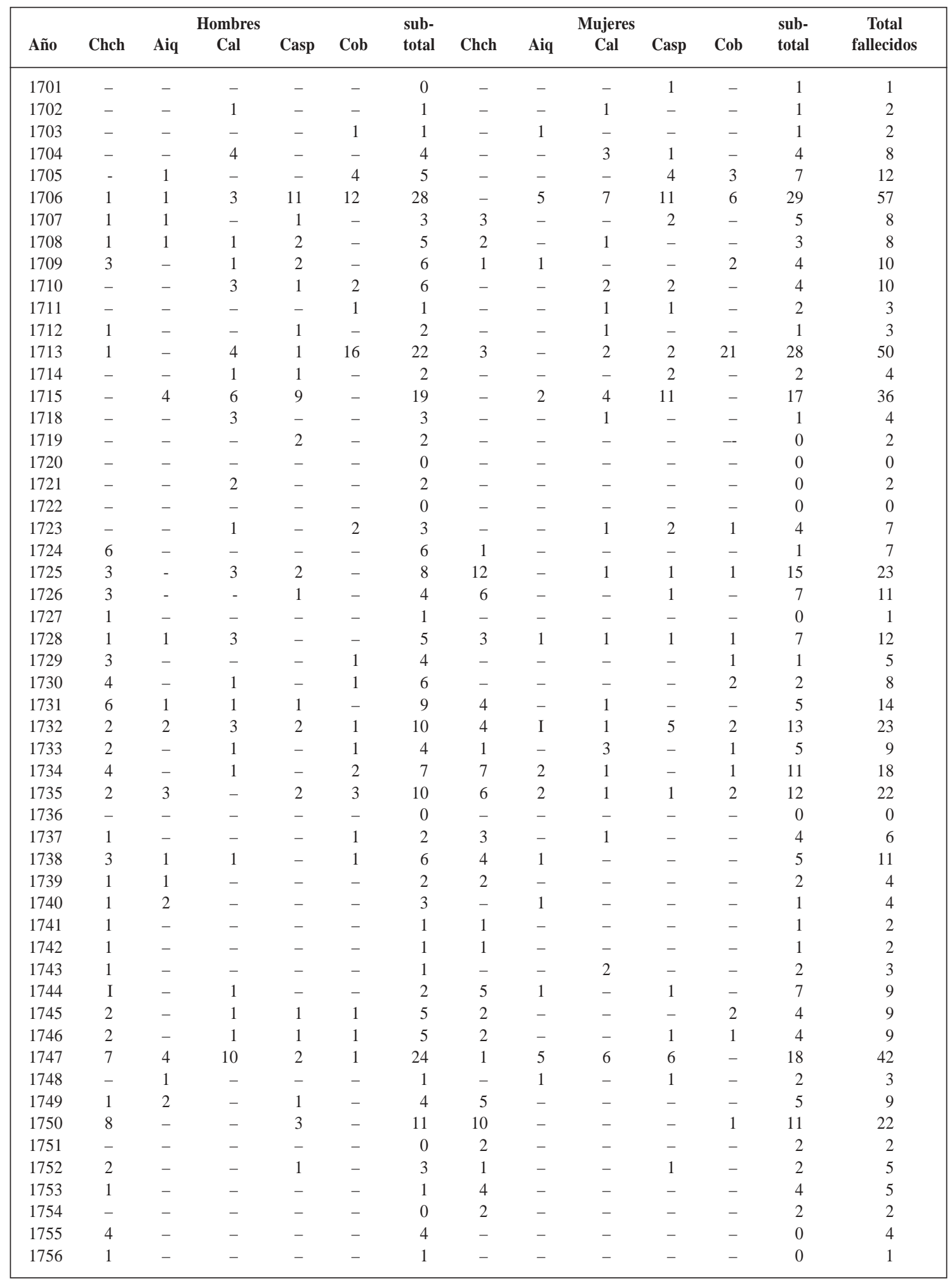

82 
Cuadro V. (Continuación)

\begin{tabular}{|c|c|c|c|c|c|c|c|c|c|c|c|c|c|}
\hline Año & Chch & Aiq & $\begin{array}{c}\text { Hombres } \\
\text { Cal }\end{array}$ & Casp & Cob & $\begin{array}{l}\text { sub- } \\
\text { total }\end{array}$ & Chch & Aiq & $\begin{array}{c}\text { Mujeres } \\
\text { Cal }\end{array}$ & Casp & Cob & $\begin{array}{l}\text { sub- } \\
\text { total }\end{array}$ & $\begin{array}{c}\text { Total } \\
\text { fallecidos }\end{array}$ \\
\hline 1757 & 1 & - & - & - & 1 & 2 & 2 & - & - & - & - & 2 & 4 \\
\hline 1758 & 1 & - & - & 1 & 3 & 5 & 2 & - & - & 2 & 1 & 5 & 10 \\
\hline 1759 & 2 & - & - & 2 & - & 4 & 2 & _ & - & - & - & 2 & 6 \\
\hline 1760 & - & - & - & 4 & 10 & 14 & 2 & - & - & 1 & 7 & 10 & 24 \\
\hline 1761 & 3 & - & - & - & - & 3 & 3 & - & - & - & - & 3 & 6 \\
\hline 1762 & - & - & - & - & - & 0 & 5 & - & - & - & - & 5 & 5 \\
\hline 1763 & - & - & 3 & - & - & 3 & 2 & - & - & - & - & 2 & 5 \\
\hline 1764 & 1 & - & 1 & - & - & 2 & 1 & 2 & - & 2 & - & 5 & 7 \\
\hline 1765 & 7 & 2 & 7 & - & 3 & 19 & 7 & 4 & 9 & 2 & - & 22 & 41 \\
\hline 1766 & 1 & - & - & 1 & - & 2 & 2 & - & - & - & - & 2 & 4 \\
\hline 1767 & - & - & - & - & - & 0 & 3 & 1 & 3 & 2 & - & 9 & 9 \\
\hline 1768 & 3 & 1 & 1 & 2 & 2 & 9 & 3 & 2 & 1 & - & - & 6 & 15 \\
\hline 1769 & 2 & 2 & 2 & - & - & 6 & 2 & - & 5 & - & 1 & 8 & 14 \\
\hline 1770 & 1 & - & 5 & 2 & - & 8 & 5 & 2 & 3 & 6 & 1 & 17 & 25 \\
\hline 1771 & 5 & 1 & 1 & - & 3 & 10 & 2 & 1 & - & - & 1 & 4 & 14 \\
\hline 1772 & 3 & - & 3 & 1 & - & 7 & 3 & - & 3 & 1 & - & 7 & 14 \\
\hline 1773 & 26 & 1 & 14 & 7 & 3 & 51 & 10 & - & 5 & 3 & 1 & 28 & 79 \\
\hline 1774 & 3 & 3 & 6 & 2 & - & 14 & 1 & 2 & - & 1 & - & 4 & 18 \\
\hline 1775 & 4 & - & 11 & - & - & 15 & 5 & 3 & 3 & - & - & 11 & 26 \\
\hline 1776 & 12 & - & 3 & 1 & 1 & 7 & 1 & - & 4 & - & - & 5 & 12 \\
\hline 1777 & 2 & - & 5 & - & - & 7 & - & - & - & - & - & 0 & 7 \\
\hline 1778 & 4 & 2 & - & - & 1 & 7 & 9 & - & 4 & - & - & 13 & 20 \\
\hline 1779 & 3 & 3 & 2 & 1 & - & 9 & 2 & 1 & 3 & 3 & - & 9 & 18 \\
\hline 1780 & 2 & - & 2 & 2 & - & 6 & 5 & - & 2 & - & - & 7 & 13 \\
\hline 1781 & 6 & - & 4 & - & - & 10 & 10 & - & 5 & - & 1 & 16 & 26 \\
\hline 1782 & 4 & 1 & 1 & - & 1 & 7 & - & 1 & 1 & - & 1 & 3 & 10 \\
\hline 1783 & 2 & - & 2 & - & - & 4 & 3 & - & 2 & - & - & 5 & 9 \\
\hline 1784 & 1 & 1 & 1 & - & - & 3 & 3 & - & 1 & 2 & 2 & 8 & 11 \\
\hline 1785 & 2 & - & 3 & - & - & 5 & 2 & - & 6 & - & 1 & 9 & 14 \\
\hline 1786 & 4 & - & 5 & - & - & 9 & - & - & 3 & - & - & 3 & 12 \\
\hline 1787 & 3 & - & 2 & - & - & 5 & 5 & 1 & 3 & - & - & 9 & 14 \\
\hline 1788 & 11 & 3 & 19 & 4 & - & 37 & 14 & 1 & 20 & 6 & - & 41 & 78 \\
\hline 1789 & - & - & 9 & - & - & 9 & 4 & 1 & 8 & - & - & 13 & 22 \\
\hline 1790 & 2 & - & 4 & - & 5 & 11 & 4 & - & 2 & - & 1 & 7 & 18 \\
\hline 1791 & 4 & 3 & 16 & 3 & - & 26 & 3 & 2 & 14 & 2 & - & 21 & 47 \\
\hline 1792 & - & - & 8 & - & 1 & 9 & 3 & 1 & 8 & 1 & 1 & 14 & 23 \\
\hline 1793 & 5 & - & 1 & - & - & 6 & 3 & 1 & 6 & - & - & 10 & 16 \\
\hline 1794 & 6 & - & 4 & 1 & - & 11 & 1 & - & 4 & 1 & - & 6 & 17 \\
\hline 1795 & 1 & 1 & 16 & - & - & 18 & 3 & - & 11 & 1 & - & 15 & 33 \\
\hline 1796 & 7 & - & 4 & - & - & 11 & 6 & 1 & 2 & 1 & - & 10 & 21 \\
\hline 1797 & 10 & - & - & - & - & 10 & 5 & - & - & - & - & 5 & 15 \\
\hline 1798 & 4 & - & 2 & - & - & 6 & 6 & - & 5 & 1 & - & 12 & 18 \\
\hline 1799 & 5 & - & 6 & - & 2 & 13 & 3 & - & 6 & - & 2 & 11 & 24 \\
\hline 1800 & 9 & - & 2 & - & - & 11 & 7 & - & 1 & - & - & 8 & 19 \\
\hline
\end{tabular}

correspondientes a los sexos y a las zonas territoriales y a los totales por bautismos, matrimonios y defunciones aunque, como indiqué al principio de este trabajo, no considero que tales números permitan, por ahora, llegar a puntualizaciones científicamente concluyentes.
11. Finalizaré este breve estudio haciendo referencia a algunos datos ya dados a conocer sobre la población atacameña en el siglo XVIII.

Según el comerciante francés Vicente Bervan o Bauver, que viajó en 1706, en Cobija "no hay más habitantes... que el cura y cerca de treinta hombres" (si consideramos la epidemia de 1713 a que 
Cuadro VI. Defunciones en San Pedro de Atacama y sus anexos.

Abreviaturas: SPAt: S. Pedro de Atacama - Ing: Ingaguasi - Soc: Socaire-Paiue Sus: Susques - Toc: Toconao

\begin{tabular}{|c|c|c|c|c|c|c|c|c|c|c|c|c|c|}
\hline Año & SPAt & Ing & $\begin{array}{c}\text { Hombres } \\
\text { Soc }\end{array}$ & Sus & Toc & $\begin{array}{l}\text { sub- } \\
\text { total }\end{array}$ & SPAt & Ing & $\begin{array}{c}\text { Mujeres } \\
\text { Soc }\end{array}$ & Sus & Toc & $\begin{array}{l}\text { sub- } \\
\text { total }\end{array}$ & $\begin{array}{c}\text { Total } \\
\text { fallecidos }\end{array}$ \\
\hline 1763 & 2 & - & - & - & I & 3 & 1 & - & - & - & 2 & 3 & 6 \\
\hline 1764 & 38 & - & - & 1 & 2 & 41 & 49 & - & - & 4 & 2 & 55 & 96 \\
\hline 1765 & 80 & - & 1 & 9 & 10 & 100 & 136 & - & 2 & 12 & 25 & 175 & 275 \\
\hline 1766 & 11 & 1 & 6 & 9 & 5 & 32 & 13 & 1 & 16 & 7 & 2 & 39 & 71 \\
\hline 1767 & 17 & 14 & - & 5 & 1 & 37 & 13 & 4 & - & 2 & 2 & 21 & 58 \\
\hline 1768 & 7 & 15 & 1 & 3 & - & 26 & 14 & 3 & 2 & 2 & 3 & 24 & 50 \\
\hline 1769 & 4 & 3 & 1 & 12 & - & 20 & 7 & - & - & 7 & - & 14 & 34 \\
\hline 1770 & 12 & - & - & 3 & - & 15 & 16 & - & - & - & - & 16 & 31 \\
\hline 1771 & 7 & 4 & 2 & 2 & 3 & 18 & 8 & - & - & 1 & 2 & 11 & 29 \\
\hline 1772 & 18 & 4 & - & - & 1 & 23 & 23 & 1 & - & - & 7 & 31 & 54 \\
\hline 1773 & 16 & 1 & 2 & 11 & 1 & 31 & 21 & - & 2 & 8 & 3 & 34 & 65 \\
\hline 1774 & 15 & - & - & 2 & 5 & 22 & 29 & - & - & 5 & 2 & $3 \mathrm{G}$ & 58 \\
\hline 1775 & 34 & 6 & 4 & 3 & 2 & 49 & $3 \mathrm{G}$ & 6 & 3 & 1 & 1 & 47 & 96 \\
\hline 1776 & 8 & 6 & - & 4 & 1 & 19 & 8 & 2 & 3 & 1 & 3 & 17 & 36 \\
\hline 1777 & 42 & 5 & 3 & 4 & I1 & G5 & 58 & 3 & 2 & 2 & 18 & 83 & 148 \\
\hline 1778 & 6 & 3 & 2 & 13 & 6 & 30 & 8 & 1 & 4 & 9 & 1 & 23 & 53 \\
\hline 1779 & 10 & 7 & - & 2 & 1 & 20 & 11 & 1 & 2 & 1 & - & 15 & 35 \\
\hline 1780 & 8 & 3 & - & - & 1 & 12 & 11 & 4 & - & - & 1 & 16 & 28 \\
\hline 1781 & 9 & 10 & - & - & 3 & 22 & 14 & 4 & - & 4 & 4 & 26 & 48 \\
\hline 1782 & 11 & 1 & - & - & 6 & 18 & 20 & 1 & - & 2 & - & 23 & 41 \\
\hline 1783 & 19 & 2 & - & 3 & 1 & 25 & 32 & 2 & - & 6 & 1 & 41 & 66 \\
\hline 1784 & 9 & - & 4 & 3 & 6 & 22 & 16 & - & - & 2 & 3 & 21 & 43 \\
\hline 1785 & 5 & - & - & 2 & 1 & 8 & 24 & - & - & 1 & 3 & 28 & 36 \\
\hline 1786 & 12 & 5 & - & - & 1 & 18 & 11 & 1 & - & 1 & - & 13 & 31 \\
\hline 1787 & 5 & - & - & 3 & 3 & 11 & 10 & - & 1 & - & 2 & 13 & 24 \\
\hline 1788 & 20 & 1 & - & 4 & - & 25 & 20 & - & - & 1 & - & 21 & 46 \\
\hline 1789 & - & - & - & - & - & 0 & - & - & - & - & - & 0 & 0 \\
\hline 1790 & - & 4 & - & - & - & 4 & - & 5 & - & - & - & 5 & 9 \\
\hline 1791 & 3 & 3 & - & - & 4 & 10 & - & - & - & - & - & 0 & 10 \\
\hline 1792 & 24 & - & 1 & 3 & 2 & 30 & 15 & - & 2 & - & 2 & 19 & 49 \\
\hline 1793 & 25 & - & 2 & 3 & I & 31 & 11 & - & 1 & 1 & 1 & 14 & 45 \\
\hline 1794 & 20 & - & - & 1 & 2 & 23 & 12 & - & - & 1 & 6 & 19 & 42 \\
\hline 1795 & 18 & - & - & 1 & 3 & 22 & 23 & - & - & - & 2 & 25 & 47 \\
\hline 1796 & 19 & - & 1 & 2 & - & 22 & 22 & - & 1 & 4 & 3 & 30 & 52 \\
\hline 1797 & 25 & - & - & 2 & 6 & 33 & 30 & - & - & 3 & 3 & 36 & 69 \\
\hline 1798 & 14 & - & - & 1 & 1 & 16 & 14 & - & - & - & 1 & 15 & 31 \\
\hline 1799 & 14 & - & - & 3 & 1 & 18 & 11 & - & - & 2 & 4 & 17 & 35 \\
\hline 1800 & 10 & - & - & 4 & 4 & 18 & 15 & - & - & 1 & 4 & 20 & 38 \\
\hline
\end{tabular}

antes nos hemos referido, hemos de creer que este informante quedó corto en sus cálculos). A Calama la designa como un villorrio habitado por diez o doce indios. Y de Chiu Chiu, de cuyo número de pobladores no nos ha dejado noticia alguna (en este punto se extravió una hoja de su manuscrito), afirma que es "un gran villorrio indígena. ${ }^{10}$

10 Pernoud, Regine: Diario inédito de un viaje a lo largo de las costas de Chile y del Perú (1706-1707), en "Boletín de la Academia Chilena de la Historia", año XXVII, N 62, primer semestre 1960 , pp. 12, 14 y 15 .
El viajero y científico Frézier, que estuvo junto a Cobija en junio de 1713 (poco antes de la mencionada epidemia), aunque no desembarcó e informa sólo a través de noticias que le dieron otros compatriotas suyos, afirma que Cobija tenía unas cincuenta habitaciones de indios; que en Calama vivirían diez o doce personas y en Chiu Chiu solamente ocho o diez. ${ }^{11}$

11 Frézier, Mr. Amadeo Francisco: Relation du voyage de la Mer du Sud aux cótes du Chili et du Perou fait pendant les annes 1712, 1713 \& 1714, París, 1732, pp. 130 y 131. 
Cuadro VII. Resumen de los bautismos, matrimonios y defunciones que figuran inscritos en la región atacameña durante el siglo XVIII.

Abreviaturas: Chiu Chiu y sus anexos (o sea, Atacama Septentrional): ASp - San Pedro de Atacama y sus anexos (Atac. Meridional): AMr.

\begin{tabular}{|c|c|c|c|c|c|c|c|c|c|c|c|c|c|c|c|c|c|}
\hline \multirow[b]{3}{*}{ Año } & \multicolumn{6}{|c|}{ Personas bautizadas } & \multirow{3}{*}{ Total } & \multirow{2}{*}{\multicolumn{3}{|c|}{ Matrimonios }} & \multirow{2}{*}{\multicolumn{6}{|c|}{$\begin{array}{cr} & \text { Personas fallecidas } \\
\text { Hombres } & \text { Mujeres }\end{array}$}} & \multirow{3}{*}{ Total } \\
\hline & \multicolumn{2}{|c|}{ Hombres } & \multirow[b]{2}{*}{$\begin{array}{l}\text { Sub- } \\
\text { total }\end{array}$} & \multicolumn{2}{|c|}{ Mujeres } & \multirow[b]{2}{*}{$\begin{array}{l}\text { Sub- } \\
\text { total }\end{array}$} & & & & & & & & & & & \\
\hline & ASp & $\mathrm{AMr}$ & & ASp & $\mathrm{AMr}$ & & & ASp & $\mathrm{AMr}$ & total & ASp & $\mathrm{AMr}$ & $\begin{array}{l}\text { Sub- } \\
\text { total }\end{array}$ & ASp & $\mathrm{AMr}$ & $\begin{array}{l}\text { Sub- } \\
\text { total }\end{array}$ & \\
\hline 1701 & 9 & - & 9 & 9 & - & 9 & 18 & 2 & - & 2 & 0 & - & 0 & 1 & - & 1 & 1 \\
\hline 1702 & 11 & - & 11 & 12 & - & 12 & 23 & 4 & - & 4 & 1 & - & 1 & 1 & - & 1 & 2 \\
\hline 1703 & 16 & - & 16 & 18 & - & 18 & 34 & 6 & - & 6 & 1 & - & 1 & 1 & - & 1 & 2 \\
\hline 1704 & 13 & - & 13 & 7 & - & 7 & 20 & 1 & - & 1 & 4 & - & 4 & 4 & - & 4 & 8 \\
\hline 1705 & 13 & - & 13 & 10 & - & 10 & 23 & 3 & - & 3 & 5 & - & 5 & 7 & - & 7 & 12 \\
\hline 1706 & 15 & - & 15 & 16 & - & 16 & 31 & 2 & - & 2 & 28 & - & 28 & 29 & - & 29 & 57 \\
\hline 1707 & 6 & - & 6 & 17 & - & 17 & 23 & 1 & - & 1 & 3 & - & 3 & 6 & - & 5 & 8 \\
\hline 1708 & 16 & - & 16 & 16 & - & 16 & 32 & 5 & - & 5 & 5 & - & 5 & 3 & - & 3 & 8 \\
\hline 1709 & 3 & - & 3 & 6 & - & 6 & 9 & 2 & - & 2 & 6 & - & 6 & 4 & - & 4 & 10 \\
\hline 1710 & 19 & - & 19 & 12 & - & 12 & 31 & 5 & - & 5 & 6 & - & 6 & 4 & - & 4 & 10 \\
\hline 1711 & 4 & - & 4 & 3 & - & 3 & 7 & 3 & - & 3 & 1 & - & 1 & 2 & - & 2 & 3 \\
\hline 1712 & 12 & - & 12 & 6 & - & 6 & 18 & 8 & - & 8 & 2 & - & 2 & 1 & - & 1 & 3 \\
\hline 1713 & 9 & - & 9 & 17 & - & 17 & 26 & 5 & - & 5 & 22 & - & 22 & 28 & - & 28 & 50 \\
\hline 1714 & 9 & - & 9 & 9 & - & 9 & 18 & 7 & - & 7 & 2 & - & 2 & 2 & - & 2 & 4 \\
\hline 1715 & 9 & 1 & 10 & 18 & 0 & 18 & 28 & 6 & - & 6 & 19 & - & 19 & 17 & - & 17 & 36 \\
\hline 1716 & 6 & - & 6 & 4 & - & 4 & 10 & 5 & - & 5 & - & - & - & - & - & - & 0 \\
\hline 1717 & 5 & - & 5 & 6 & - & 6 & 11 & 4 & - & 4 & - & - & - & - & - & - & 0 \\
\hline 1718 & 11 & - & 11 & 10 & - & 10 & 21 & - & - & 0 & 3 & - & 3 & 1 & - & 1 & 4 \\
\hline 1719 & 7 & - & 7 & 4 & - & 4 & 11 & - & - & 0 & 2 & - & 2 & 0 & - & 0 & 2 \\
\hline 1720 & 1 & - & 1 & 0 & - & 0 & 1 & - & - & 0 & 0 & - & 0 & 0 & - & 0 & 0 \\
\hline 1721 & 13 & - & 13 & 10 & - & 10 & 23 & - & - & 0 & 2 & - & 2 & 0 & - & 0 & 2 \\
\hline 1722 & 7 & - & 7 & 5 & - & 5 & 12 & - & - & 1 & 0 & - & 0 & 0 & - & 0 & 0 \\
\hline 1723 & 3 & - & 3 & 8 & - & 8 & 11 & 0 & - & 0 & 3 & - & 3 & 4 & - & 4 & 7 \\
\hline 1724 & 5 & - & 5 & 2 & - & 2 & 7 & 2 & - & 2 & 6 & - & 6 & 1 & - & 1 & 7 \\
\hline 1725 & 14 & - & 14 & 9 & - & 9 & 23 & - & - & 1 & 8 & - & 8 & 15 & - & 15 & 23 \\
\hline 1726 & 13 & - & 13 & 12 & - & 12 & 25 & - & - & 1 & 4 & - & 4 & 7 & - & 7 & 11 \\
\hline 1727 & 5 & - & 5 & 9 & - & 9 & 14 & 2 & - & 2 & 1 & - & 1 & 0 & - & 0 & 1 \\
\hline 1728 & 6 & - & 6 & 14 & - & 14 & 20 & 6 & - & 6 & 5 & - & 5 & 7 & - & 7 & 12 \\
\hline 1729 & 18 & - & 18 & 16 & - & 16 & 34 & 2 & - & 2 & 4 & - & 4 & 1 & - & 1 & 5 \\
\hline 1730 & 6 & - & 6 & 3 & - & 3 & 9 & - & - & 0 & 6 & - & 6 & 2 & - & 2 & 8 \\
\hline 1731 & 9 & - & 9 & 6 & - & 6 & 15 & - & - & 0 & 9 & - & 9 & 5 & - & 5 & 14 \\
\hline 1732 & 5 & - & 5 & 5 & - & 5 & 10 & - & - & 0 & 10 & - & 10 & 13 & - & 13 & 23 \\
\hline 1733 & 10 & - & 10 & 13 & - & 13 & 23 & - & - & 0 & 4 & - & 4 & 5 & - & 5 & 9 \\
\hline 1734 & 4 & - & 4 & 4 & - & 4 & 8 & 3 & - & 3 & 7 & - & 7 & 11 & - & 11 & 18 \\
\hline 1735 & 9 & - & 9 & 5 & - & 5 & 14 & 2 & - & 2 & 10 & - & 10 & 12 & - & 12 & 22 \\
\hline 1736 & 13 & - & 13 & 11 & - & 11 & 24 & - & - & 0 & 0 & - & 0 & 0 & - & 0 & 0 \\
\hline 1737 & 15 & 17 & 32 & 14 & 9 & 23 & 55 & - & - & 0 & 2 & - & 2 & 4 & - & 4 & 6 \\
\hline 1738 & 7 & 36 & 43 & 13 & 35 & 48 & 91 & 3 & - & 3 & 6 & - & 6 & 5 & - & 5 & 11 \\
\hline 1739 & 7 & 31 & 38 & 14 & 31 & 45 & 83 & 5 & - & 5 & 2 & - & 2 & 2 & - & 2 & 4 \\
\hline 1740 & 14 & 26 & 40 & 13 & 20 & 33 & 73 & - & - & 1 & 3 & - & 3 & 1 & - & 1 & 4 \\
\hline 1741 & 6 & 26 & 32 & 2 & 31 & 33 & 65 & 4 & - & 4 & 1 & - & 1 & 1 & - & 1 & 2 \\
\hline 1742 & 11 & 13 & 24 & 15 & 27 & 42 & 66 & 4 & - & 4 & 1 & - & 1 & 1 & - & 1 & 2 \\
\hline 1743 & 18 & 43 & 61 & 11 & 47 & 58 & 119 & - & - & 1 & 1 & - & 1 & 2 & - & 2 & 3 \\
\hline 1744 & 11 & 25 & 36 & 21 & 25 & 46 & 82 & 6 & - & 6 & 2 & - & 2 & 7 & - & 7 & 9 \\
\hline 1745 & 10 & 31 & 41 & 15 & 34 & 49 & 90 & 4 & - & 4 & 5 & - & 5 & 4 & - & 4 & 9 \\
\hline 1746 & 11 & 29 & 40 & 8 & 31 & 39 & 79 & 0 & - & 0 & 5 & - & 5 & 4 & - & 4 & 9 \\
\hline 1747 & 3 & 22 & 25 & 6 & 35 & 41 & 66 & - & - & 1 & 24 & - & 24 & 18 & - & 18 & 42 \\
\hline 1748 & 9 & 34 & 43 & 8 & 28 & 36 & 79 & 2 & - & 2 & 1 & - & 1 & 2 & - & 2 & 3 \\
\hline 1749 & 7 & 35 & 42 & 7 & 43 & 50 & 92 & 3 & - & 3 & 4 & - & 4 & 5 & - & 5 & 9 \\
\hline 1750 & 8 & 35 & 43 & 7 & 37 & 40 & 83 & 6 & - & 6 & 11 & - & 11 & 11 & - & 11 & 22 \\
\hline
\end{tabular}


Cuadro VII. (Continuación)

\begin{tabular}{|c|c|c|c|c|c|c|c|c|c|c|c|c|c|c|c|c|c|}
\hline \multirow[b]{3}{*}{ Año } & \multicolumn{6}{|c|}{ Personas bautizadas } & \multirow{3}{*}{ Total } & \multicolumn{3}{|c|}{ Matrimonios } & \multirow{2}{*}{\multicolumn{6}{|c|}{ Personas fallecidas }} & \multirow{3}{*}{ Total } \\
\hline & \multicolumn{2}{|c|}{ Hombres } & \multirow[b]{2}{*}{$\begin{array}{l}\text { Sub- } \\
\text { total }\end{array}$} & \multicolumn{2}{|c|}{ Mujeres } & \multirow[b]{2}{*}{$\begin{array}{l}\text { Sub- } \\
\text { total }\end{array}$} & & \multicolumn{3}{|c|}{ celebrados } & & & & & & & \\
\hline & ASp & $\mathrm{AMr}$ & & ASp & $\mathrm{AMr}$ & & & ASp & $\mathrm{AMr}$ & total & ASp & AMr & $\begin{array}{l}\text { Sub- } \\
\text { total }\end{array}$ & ASp & $\mathrm{AMr}$ & $\begin{array}{l}\text { Sub- } \\
\text { total }\end{array}$ & \\
\hline 1751 & 8 & 41 & 49 & 2 & 40 & 42 & 91 & 7 & - & 7 & 0 & - & 0 & 2 & - & 2 & 2 \\
\hline 1752 & 7 & 41 & 48 & 13 & 37 & 50 & 98 & 4 & - & 4 & 3 & - & 3 & 2 & - & 2 & 5 \\
\hline 1753 & 7 & 48 & 55 & 12 & 45 & 57 & 112 & 5 & - & 5 & 1 & - & 1 & 4 & - & 4 & 5 \\
\hline 1754 & 9 & 38 & 47 & 10 & 31 & 41 & 88 & 5 & - & 5 & 0 & - & 0 & 2 & - & 2 & 2 \\
\hline 1755 & 14 & 39 & 53 & 12 & 41 & 53 & 106 & 4 & - & 4 & 4 & - & 4 & 0 & - & 0 & 4 \\
\hline 1756 & 5 & 39 & 44 & 5 & 59 & 64 & 108 & 1 & - & 1 & 1 & - & 1 & 0 & - & 0 & I \\
\hline 1757 & 10 & 19 & 29 & 16 & 29 & 45 & 74 & 2 & - & 2 & 2 & - & 2 & 2 & - & 2 & 4 \\
\hline 1758 & 14 & 57 & 71 & 6 & 33 & 39 & 110 & 11 & - & 11 & 5 & - & 5 & 5 & - & 5 & 10 \\
\hline 1759 & 9 & 34 & 43 & 5 & 30 & 35 & 78 & 8 & - & 8 & 4 & - & 4 & 2 & - & 2 & 6 \\
\hline 1760 & 1 & 7 & 8 & 3 & 6 & 9 & 17 & 9 & - & 9 & 14 & - & 14 & 10 & - & 10 & 24 \\
\hline 1761 & 9 & 35 & 44 & 8 & 39 & 47 & 91 & 3 & - & 3 & 3 & - & 3 & 3 & - & 3 & 6 \\
\hline 1762 & 4 & 34 & 38 & 9 & 36 & 45 & 83 & 10 & - & 10 & 0 & - & 0 & 5 & - & 5 & 5 \\
\hline 1763 & 0 & 53 & 53 & 0 & 72 & 72 & 125 & 5 & 11 & 16 & 3 & 3 & 6 & 2 & 3 & 5 & 11 \\
\hline 1764 & 13 & 37 & 50 & 12 & 57 & 69 & 119 & 3 & 9 & 12 & 2 & 41 & 43 & 5 & 55 & 60 & 103 \\
\hline 1765 & 6 & 40 & 46 & 3 & 54 & 57 & 103 & 1 & 7 & 8 & 19 & 100 & 119 & 22 & 175 & 197 & 316 \\
\hline 1766 & 14 & 39 & 53 & 12 & 56 & 68 & 121 & 16 & 17 & 33 & 2 & 32 & 34 & 2 & 39 & 41 & 75 \\
\hline 1767 & 18 & 41 & 59 & 18 & 45 & 63 & 122 & 5 & 20 & 25 & 0 & 37 & 37 & 9 & 21 & 30 & 67 \\
\hline 1768 & 16 & 39 & 55 & 22 & 42 & 64 & 119 & 2 & 20 & 22 & 9 & 26 & 35 & 6 & 24 & 30 & 65 \\
\hline 1769 & 23 & 48 & 71 & 20 & 49 & 69 & 140 & 4 & 12 & 16 & 6 & 20 & 26 & 8 & 14 & 22 & 48 \\
\hline 1770 & 19 & 38 & 57 & 12 & 50 & 62 & 119 & 5 & 18 & 23 & 8 & 15 & 23 & 17 & 16 & 33 & 56 \\
\hline 1771 & 12 & 28 & 40 & 11 & 33 & 44 & 84 & 2 & 8 & 10 & 10 & 18 & 28 & 4 & 11 & 15 & 43 \\
\hline 1772 & 25 & 53 & 78 & 14 & 56 & 70 & 148 & 8 & 8 & 16 & 7 & 23 & 30 & 7 & 31 & 38 & 68 \\
\hline 1773 & 16 & 38 & 54 & 13 & 45 & 58 & 112 & 17 & 16 & 33 & 51 & 31 & 82 & 28 & 34 & 62 & 144 \\
\hline 1774 & 24 & 37 & 61 & 13 & 44 & 57 & 118 & 17 & 13 & 30 & 14 & 22 & 36 & 4 & 36 & 40 & 76 \\
\hline 1775 & 18 & 45 & 63 & 15 & 42 & 57 & 120 & 9 & 11 & 20 & 15 & 49 & 64 & 11 & 47 & 58 & 122 \\
\hline 1776 & 16 & 45 & 61 & 12 & 43 & 55 & 116 & 3 & 18 & 21 & 7 & 19 & 26 & 5 & 17 & 22 & 48 \\
\hline 1777 & 17 & 33 & 50 & 6 & 42 & 48 & 98 & 0 & 18 & 18 & 7 & 65 & 72 & 0 & 83 & 83 & 155 \\
\hline 1778 & 21 & 40 & 61 & 8 & 49 & 57 & 118 & 13 & 24 & 37 & 7 & 30 & 37 & 13 & 23 & 36 & 73 \\
\hline 1779 & 18 & 39 & 57 & 11 & 42 & 53 & 110 & 12 & 24 & 36 & 9 & 20 & 29 & 9 & 15 & 24 & 53 \\
\hline 1780 & 24 & 41 & 65 & 19 & 44 & 63 & 128 & 6 & 14 & 20 & 6 & 12 & 18 & 7 & 16 & 23 & 41 \\
\hline 1781 & 14 & 50 & 64 & 6 & 51 & 57 & 121 & 8 & 21 & 29 & 10 & 22 & 32 & 16 & 26 & 42 & 74 \\
\hline 1782 & 19 & 52 & 71 & 23 & 56 & 79 & 150 & 8 & 19 & 27 & 7 & 18 & 25 & 3 & 23 & 26 & 51 \\
\hline 1783 & 14 & 50 & 64 & 9 & 48 & 57 & 121 & 5 & 19 & 24 & 4 & 25 & 29 & 5 & 41 & 46 & 75 \\
\hline 1784 & 31 & 50 & 81 & 21 & 42 & 63 & 144 & 2 & 18 & 20 & 3 & 22 & 25 & 8 & 21 & 29 & 54 \\
\hline 1785 & 11 & 41 & 52 & 14 & 48 & 62 & 114 & 1 & 14 & 15 & 5 & 8 & 13 & 9 & 28 & 37 & 50 \\
\hline 1786 & 13 & 46 & 59 & 19 & 63 & 82 & 141 & 7 & 11 & 18 & 9 & 18 & 27 & 3 & 13 & 16 & 43 \\
\hline 1787 & 19 & 40 & 59 & 22 & 58 & 80 & 139 & 10 & 19 & 29 & 5 & 11 & 16 & 9 & 13 & 22 & 38 \\
\hline 1788 & 12 & 35 & 47 & 16 & 24 & 40 & 87 & 9 & 1 & 10 & 37 & 25 & 62 & 41 & 21 & 62 & 124 \\
\hline 1789 & 11 & 23 & 34 & 7 & 18 & 25 & 59 & 13 & 0 & 13 & 9 & 0 & 9 & 13 & 0 & 13 & 22 \\
\hline 1790 & 16 & 0 & 16 & 16 & 0 & 16 & 32 & 4 & - & 4 & 11 & 4 & 15 & 7 & 5 & 12 & 27 \\
\hline 1791 & 26 & 7 & 33 & 21 & 6 & 27 & 60 & 11 & - & 11 & 26 & 10 & 36 & 21 & 0 & 21 & 57 \\
\hline 1792 & 29 & 48 & 77 & 15 & 60 & 75 & 152 & 11 & - & 11 & 9 & 30 & 39 & 14 & 19 & 33 & 72 \\
\hline 1793 & 13 & 64 & 77 & 21 & 43 & 64 & 141 & 9 & - & 9 & 6 & 31 & 37 & 10 & 14 & 24 & 61 \\
\hline 1794 & 19 & 60 & 79 & 27 & 61 & 88 & 167 & 12 & - & 12 & 11 & 23 & 34 & 6 & 19 & 25 & 59 \\
\hline 1795 & 17 & 43 & 60 & 12 & 34 & 46 & 106 & 14 & - & 14 & 18 & 22 & 40 & 15 & 25 & 40 & 80 \\
\hline 1796 & 1 & 35 & 36 & 0 & 36 & 36 & 72 & 10 & - & 10 & 11 & 22 & 33 & 10 & 30 & 40 & 73 \\
\hline 1797 & 15 & 61 & 76 & 16 & 51 & 67 & 143 & 12 & - & 12 & 10 & 33 & 43 & 5 & 36 & 41 & 84 \\
\hline 1798 & 18 & 48 & 66 & 3 & 46 & 49 & 115 & 3 & - & 3 & 6 & 16 & 22 & 12 & 15 & 27 & 49 \\
\hline 1799 & 30 & 35 & 65 & 26 & 43 & 69 & 134 & 17 & - & 17 & 13 & 18 & 31 & 11 & 17 & 28 & 59 \\
\hline 1800 & 22 & 61 & 83 & 13 & 57 & 70 & 153 & 12 & - & 12 & 11 & 18 & 29 & 8 & 20 & 28 & 57 \\
\hline
\end{tabular}


Según las revisitas efectuadas hasta el año 1762, la provincia de Atacama contaba con 1632 personas. En cambio, en el empadronamiento de la revisita del partido de Atacama en 1787, se contabilizaron 3658 personas (1805 hombres y 1853 mujeres). En cuanto a los hombres, 1408 correspondían a la zona meridional, o sea, a la de San Pedro de Atacama y sus anexos, y 397 a la septentrional, de Chiu Chiu y sus anexos. Y respecto a las mujeres, 324 correspondían a la zona septentrional y 1529 a la meridional. En consecuencia, 721 personas fueron censadas en la zona de Chiu Chiu y anexos, y 2937 personas en San Pedro de Atacama y anexos. ${ }^{12}$

El siguiente cuadro VIII visualiza los datos anteriores.

Pedro Vicente Cañete y Domínguez se refirió probablemente a los datos de esta última revisita, ya que escribía en 1787, pero erróneamente anotó 3657 habitantes para el total de la región atacameña, de los que 2936 los atribuía a Atacama la Alta y sus anexos y 721 a la jurisdicción de Chiu Chiu, en la cual dicho autor comprende a la explotación metalífera de Conchi. ${ }^{13}$

En cuanto a los datos referentes a la revisita, conviene hacer notar las dificultades que presentaba su obtención, pues ya en los correspondientes documentos (cita 12) se señala textualmente "muchos del Repartimiento de San Pedro de Atacama viven radicados de inmemorable tiempo en dife-

Cuadro VIII. Distribución de la población del Partido de Atacama (revisita del año 1787)

\begin{tabular}{|lccc|}
\hline & $\begin{array}{c}\text { Chiu Chiu } \\
\text { y anexos }\end{array}$ & $\begin{array}{c}\text { San Pedro de } \\
\text { Atacama y anexos }\end{array}$ & Totales \\
\hline Hombres & 397 & 1408 & 1805 \\
Mujeres & 324 & 1529 & 1853 \\
Totales & 721 & 2937 & 3658 \\
\hline
\end{tabular}

12 Casassas Cantú, José María: Obra citada La Región Atacameña..., tomo I, p. 77, según documentos de la Biblioteca de la Real Academia de la Historia, de Madrid, Colección Mata Linares tomo XXV, hoja 119, y tomo XIII, hoja 26 vuelta.

13 Cañete y Domínguez, Pedro Vicente: Obra citada Guía histórica... de la Provincia de Potosí, pp. 264 y 265. rentes lugares de la jurisdicción de Tucumán, y tan distantes de los de su origen que les ha sido indispensable la demora para venir hasta ellos a ser empadronados". Lo que, por otra parte, queda confirmado por el doctor don Vicente Anastasio de Isasmendi, cura de Calchaqui, quien en un informe suscrito en Salta el día 9 de abril de 1791, manifiesta que "...de muchos años a esta parte residen en aquella mi doctrina indios que tributan a la provincia de Atacama, los más de ellos nativos de aquel distrito y descendientes de los que se trasladaron, sujetos enteramente en lo espiritual a la citada mi doctrina..." y en el mismo expediente se relacionan diversos indios procedentes de distintos ayllos de San Pedro de Atacama y de los anexos de dicho curato que, en aquel año 1791, estaban residiendo en variados lugares de la jurisdicción de Salta y de Tucumán. Esta última información, que hemos de agradecer al $\mathrm{Pa}$ dre George Serracino, y procede a su vez de atención del Dr. John V. Murra, se encuentra en el Archivo General de la Nación Argentina, Buenos Aires, Catálogo Nuevo 30-4-9, Catálogo Viejo Interior, legajo 33, expediente 33.

Por último, Antonio de Alcedo publicó en 1786 el primer tomo de su Diccionario Geográfico-Histórico, en el cual atribuía a Atacama, provincia (o partido), unos 2500 habitantes. ${ }^{14}$

Concluiremos destacando que el empadronamiento del año 1787, antes detallado, constituye un dato preciso sobre la gran desproporción poblacional que siempre existió, durante la administración española, entre las regiones del litoral y de la hoya del río Loa en relación con toda la zona del gran salar de Atacama y sus tierras adyacentes, desproporción que, por otra parte, queda evidenciada también en los datos demográficos aportados en este trabajo, procedentes de los registros parroquiales, y que se aprecia notablemente en el cuadro-resumen VII.

Antofagasta, octubre 1972 - febrero 1974.

\footnotetext{
14 Alcedo Antonio de: Diccionario Geográfico-Histórico de las Indias Occidentales o América..., Madrid, 5 tomos, 1786-1789; en tomo I, p. 169.
} 